\title{
Theoretical prerequisites of the possibility to influence the noise of the power unit of machines for various purposes
}

\author{
Andrey Ashcheulov ${ }^{1 *}$, Andrey Kudrevatykh ${ }^{1}$, Alexander Podgorny ${ }^{1}$, Andrey Vinidiktov ${ }^{1}$, \\ and Ardak Karipzhanova ${ }^{2}$ \\ ${ }^{1}$ T.F. Gorbachev Kuzbass State Technical University, Vesennyaya St. 28, Kemerovo, Russia \\ ${ }^{2}$ Kazakh Humanitarian Law Innovative University, EKR, Semey, 11 Mangilik st., Republic of \\ Kazakstan
}

\begin{abstract}
The existing economic necessity to increase production efficiency while reducing production costs requires using all opportunities to reduce the noise of equipment used in various industries, including road construction. At the same time, the requirements for the low-noise equipment production should be applied both to road construction machines manufacturers and to engines manufacturers. Numerous studies of the acoustic characteristics of road construction equipment allow noting that the largest part of increased noise sources is located in the engine compartment. At the same time, the engine and its gas exchange systems emit the most amount of the acoustic energy.
\end{abstract}

\section{Introduction}

The most effective way to reduce noise quickly and significantly is to reduce the most intense noise produced by the machine. In this situation, reducing the engine noise and muffling the exhaust system well is equivalent to reduction of noise of the entire road construction machine (RCM), and in a complex way, both external and internal noise. [1, 2, 3]

The pattern of acoustic radiation of road construction machines of this type is similar to the acoustic radiation of a truck.

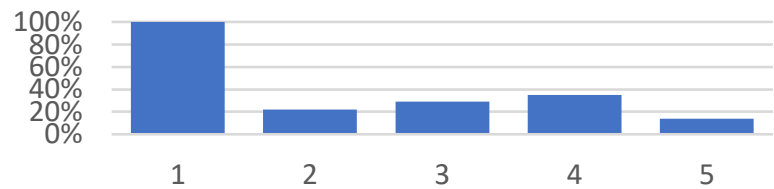

Fig. 1. The overall balance of the grader acoustic power: 1-grader; 2-transmission; 3-engine; 4exhaust; intake.

\footnotetext{
*Corresponding author: ascheulovas@kuzstu.ru
} 
As practice shows, in many cases, this possibility is available, since most road construction machines are designed without taking into account the necessity to obtain the required vibroacoustic characteristics. The problems of noise reduction are solved further in the process of upgrading the basic model with limited design capabilities, constrained by considerations of economic feasibility of changing the configuration of the machine and the technology of its mass production. $[4,5,6]$

The works of national and foreign scientists have shown that there is a reserve in improving acoustic performance for engines used as power units of road construction machines $[7,8,9]$.

A properly designed and acoustically tuned engine can have from 5 to $8 \mathrm{dBA}$ less sound power than a typical modern internal combustion engine with similar economic and power indicators $[10,11,12]$.

However, the attempts to implement this reserve by upgrading the design of already used in production engines face serious difficulties, associated with the necessity to carry out complex works on vibroacoustic refinement of the working process and the design of the main elements and engine systems, the implementation of the results of which requires significant, technically complex and expensive design changes, which in most cases is economically unacceptable in mass production conditions. [13, 14, 15]

The most complete potential of the engine design acoustic improvement can be used only on the condition that the engine from the initial stages of design will be designed taking into account the need to obtain the specified characteristics of vibroacoustic indicators, along with the specified performance and efficiency characteristics. That is, the engine of road construction machines should be designed from the very beginning as lownoise one. At the same time, along with the well-known measures to reduce the noise of internal combustion engines of road construction machines, (such as: reducing the splits in the cylinder-piston group, changing the diameters of the nozzle and plunger, increasing the rigidity of body parts, the use of floating oil pan fixation, the use of effective intake and exhaust silencers, etc), it is possible to reduce noise of road construction machines power units by purposefully changing the engine parameters and choosing the most favourable economic and technical options to comply with the limit values of acoustic indicators. [5, 6, 7]

\section{Results and discussion}

The question solution of optimal ways to reduce the noise of self-propelled road construction machines and their power units should be considered taking into account functional features of these machines and units; therefore, it is possible to divide road construction equipment into two conditional groups. These groups do not include machines which working bodies are sources of increased acoustic radiation, the reduction of which in each particular case requires a special approach, which is not the purpose of this work. One of these groups includes machines which working functions are associated with a large volume of transport operations, involving the movement of goods or materials over significant distances in the traffic flow. This group includes machines for the transport and distribution of bonding material, self-propelled scrapers, concrete mixers, truck cranes, etc.

Such road construction machines are manufactured based on production cars and are equipped with their power units.

The pattern of acoustic radiation of road construction machines of this type is similar to the acoustic radiation of a truck. 


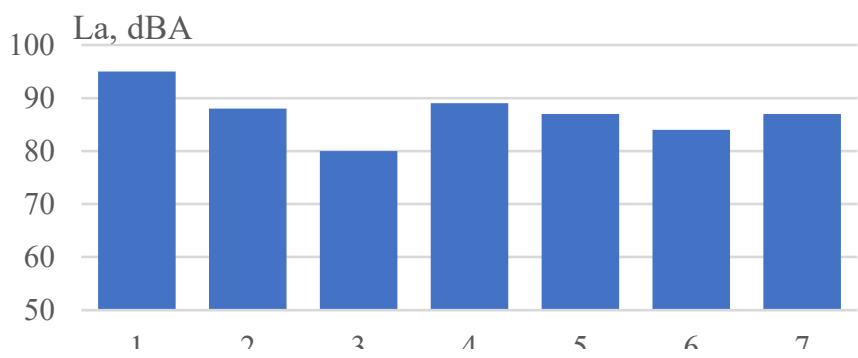

Fig. 2. The balance of truck noise sources: 1-general level; 2-internal combustion engine; 3-intake system; 4-exhaust system; 5 - engine cooling fan; 6-transmission; 7 - tires

Therefore, to solve the problems of reduction and normalization of road construction machines noise, the design, driving modes, and the mechanism of noise generation of which are similar to cars, it is advisable to use the methods that are used in the car industry, studied and described in a large number of national and foreign authors works.

For another group of machines, which includes graders, loaders, rollers, asphalt and pipe-laying machines, marking machines, etc., the transport and operating modes of which are not associated with high speeds, such sources of acoustic radiation as tire noise, transmission noise, noise, arising from the flow of oncoming air around the machine are not specific. In fact, the efficiency of such road construction machines is determined by the acoustic radiation generated by the engine and its gas exchange systems, for an average grader it is up to $78 \%$ of the total acoustic energy.

In this situation, to reduce the noise of the power unit and to muffle the exhaust system well is equivalent to reducing the noise of the entire RCM, and in a complex way, both internal and external noise. Only if this is not possible, it is advisable to consider reducing the noise of the car due to the sound insulation of the engine compartment and the control cabin.

In principle, it is not difficult to create internal combustion engines that have acoustic indicators that allow them to be attributed to secondary sources of noise of mobile cars. Another question is the extent to which such engines will meet the other requirements imposed on them by the specifics of the operation and operation of the machine on which they are used.

Considering the set of parameters that determine the power of the engine:

$$
N e=\frac{1}{30 \cdot \tau} \cdot P e \cdot n \cdot\left(i V_{h}\right)
$$

where $\tau$ is the engine cycle;

$P e$ - average effective pressure, $\mathrm{MPa}$;

$n$-speed of the crankshaft rotation, min-1;

$i V h$ is the working volume of the engine, 1 ,

it is possible to conclude that for a given engine cycle, it is possible to obtain effective power for any combination of the values $P e, n, i \mathrm{Vh}$, as long as their product is equal to $30 \cdot \tau \cdot \mathrm{Ne}$, that is:

$$
P e \cdot n \cdot i V_{h}=30 \cdot \tau \cdot N e
$$

Making a decision on how to get a given effective power is the key question, since its weight and size and dynamic performance, as well as the efficiency of the engine and the entire machine on which it is installed, depend crucially on this. In addition to the above, it 
should be noted that this actually solves the question of the level of vibroacoustic activity of the future engine. Currently, it is established that the method of increasing the effective power of an engine as follows affects the amount of sound power emitted by it $P w$.

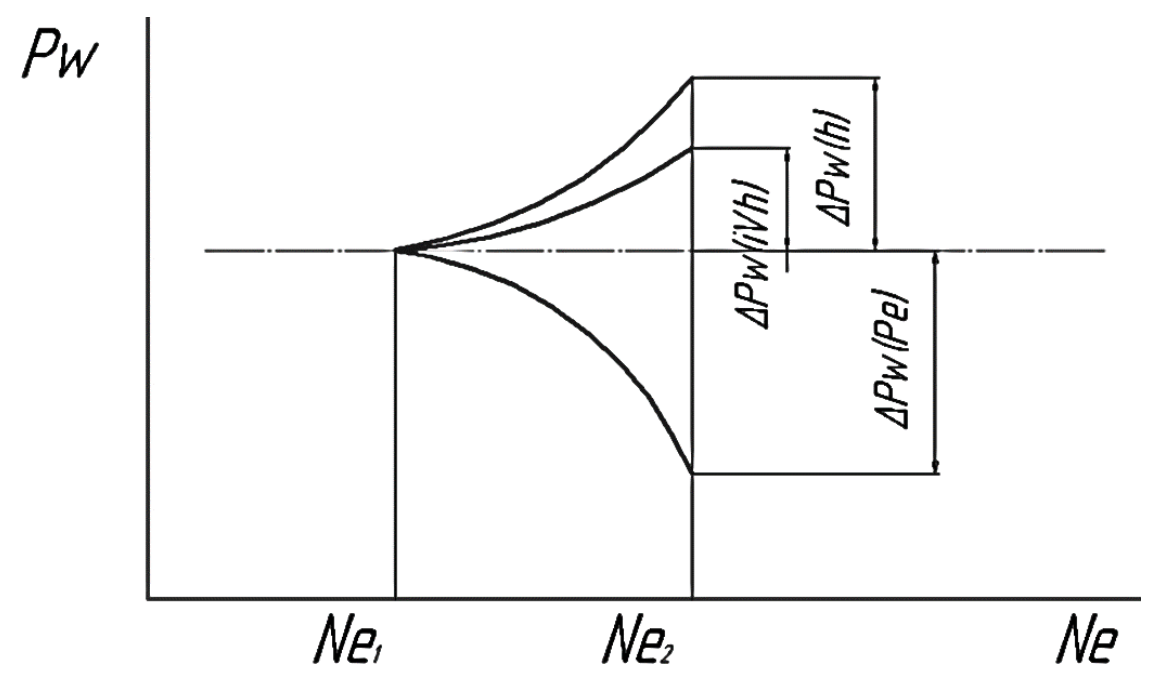

Fig. 3. The influence of the method to obtain the effective power of an engine on the sound energy emitted by it

Here:

$\Delta P_{w(n)}=10 \cdot \lg \left(\frac{n}{n_{1}}\right)^{3}$ the incrementation of the sound power level when the internal combustion engine is accelerated at the speed of rotation;

$\Delta P_{w\left(i V_{h}\right)}=10 \cdot \lg \left(\frac{i \cdot V_{h}}{i \cdot V_{h}}\right)^{2}-$ the incrementation of the sound power level when the working volume increases;

$\Delta P_{w(P e)}=10 \cdot \lg \left(\frac{P e}{P e}\right)^{-7}$ - the incrementation of the sound power level when the internal combustion engine is boosted by pressure charging.

It should be noted that high-quality pressure charging always reduces the structural engine noise levels. The quantitative measure of reduction depends on the accepted method of organizing the working process in the diesel engine, as well as on the degree of pressure charging. The above expression is true for diesels with an undivided combustion chamber with a volume pariental mixture formation at an average pressure charging $\left(\pi_{\kappa}=2.0\right)$.

With simultaneous variation of all three parameters:

$$
\Delta P w=30 \cdot \lg \frac{n}{n_{1}}+20 \cdot \lg \frac{\left(i \cdot V_{h}\right)}{\left(i \cdot V_{h}\right)_{1}}-70 \cdot \lg \frac{P e}{P e_{1}}
$$

a method of noise reduction common in the car engine industry is clearly seen, when the engine is derated at the speed of rotation, and the necessary power is restored by applying pressure charging. Both measures lead to the reduction of the power unit noise.

The main difficulty in creating low-noise car engines, the work of which is associated with the movement of cargo or people over long distances at speeds that allow to observe the traffic flow mode, is that to ensure high functional, economic and dynamic qualities of the car, the engine used in it must have significant power reserve and at the same time be light, have minimal dimensions and have high pick-up speed. 
An engine with a minimum working volume will have such qualities, the decrease of which in most cases is compensated by the increase in the formal rotational rate of the crankshaft or pressure charging. In this situation, it is necessary to deal with an initially acoustically highly active mechanism with acoustic tuning of the engine, to reduce the noise of which it is necessary to work out the design of its body elements and working process carefully etc., agree in advance with the limited possibilities for improving its hydroacoustic characteristics.

In contrast to the car, the road construction machines specific functioning is such that their power units do not require high accelerating ability, and the engine weight affects the efficiency of the machine to a lesser extent. There are more opportunities to put together a larger power unit on the car. The operating speeds of the additional power take-off box are limited by the control capabilities, the speed range is narrow. For example, for a motor grader, which traction mode is the main production mode, the maximum movement speed and scraping of the ground is $7-8 \mathrm{~km} / \mathrm{h}$. At the same time, due to the low operating speeds, grader engines, as a rule, operate not at formal speeds, but at significantly lower speeds (depending on the transmission used, $\left.\eta_{e}=(0,51-0,87) \eta_{f o r}\right)$ ). The operation of the engine in such modes is accompanied by an increased fuel consumption of up to $25 \%$ and maximum power use.

Low operating speeds, low requirements for dynamic qualities, and the absence of strict restrictions on weight and size indicators characterize the working conditions of a number of RCM types. So, for self-propelled rollers, depending on their type, the maximum values of working speeds are $2-8 \mathrm{~km} / \mathrm{h}$; for asphalt and pipe-laying machines the maximum values of working speeds do not exceed $2.5 \mathrm{~km} / \mathrm{h}$; for self-propelled loaders, during loading and unloading operations $-5-10 \mathrm{~km} / \mathrm{h}$. In addition, the working nature of these machines involves the use of additional masses to increase their weight or used as counterweights; for example, for self-propelled rollers ballasts are used, the mass of which, depending on the type of roller, is from 10 to $500 \%$ of the machine mass.

Therefore, the requirements for weight, size, and dynamic qualities that ensure the ability to switch from one speed mode to another in a minimum time are not a priority for a number of road construction machines, which work is not associated with a large volume of transport operations.

In this regard, the possible options for providing the required power of the RCM power unit allow choosing an acoustically more favourable combination of the parameters $P e, n$, $\left(i V_{h}\right)$ for its engine.

Unlike automobile diesels, here the option with a minimum speed of rotation looks more realistic (of course, minimization should take into account acceptable engine weight and size parameters and speed parameters of the machine), which corresponds to the design of an internal combustion engine with minimal vibration and acoustic activity.

The simplest calculation shows that for road construction transport the use of an engine with a moderately (1.2-1.3 times) reduced nominal speed (up to $n=1200-1500 \mathrm{~min}^{-1}$ ) with an average pressure charging will allow, with unchanged weight and size parameters, to have power units that generate acoustic energy 4-6 dB less than existing engines. This will allow having the acoustic characteristics of most RCM that meet not only the current, but also the future standards, mainly without the use of expensive and complicating the noise suppression of operating machines. The use of them, in this case, is advisable as an additional one, to create the comfortable ergonomic environment at the operators' workplaces.

The use of engines with a reduced rotation rate on road construction machines allows using high-speed modes in which their power is not fully used, while the speeds of the machines meet the existing requirements for high-speed modes. 
So, for example, for the average motor grader, the theoretical speeds of movement in the operating mode are determined by the formula:

$$
V_{t}=\frac{0,377 \cdot R_{S t} \cdot n}{i_{T R}}
$$

where $\mathrm{n}-$ is the engine crankshaft speed, $\mathrm{min}^{-1}$;

$\mathrm{R}_{\mathrm{ST}}$ - static radius of the wheel, $\mathrm{m}$;

$\mathrm{I}_{\mathrm{TR}}$ - gear transmission ratio,

with the speed mode of the engine close to the nominal $\mathrm{n}=1500 \mathrm{~min}^{-1}$ are:

- in first gear $-4.6 \mathrm{~km} / \mathrm{h}$;

- in second gear $-6.3 \mathrm{~km} / \mathrm{h}$;

- in third gear $-11.5 \mathrm{~km} / \mathrm{h}$.

\section{Conclusion}

In the conclusion, it should be noted that, in relation to a certain group of RCM, it is possible to reduce noise by reducing the vibroacoustic activity of their power units. Taking into account the specifics of such RCM operation, as well as the requirements for their power units, which do not determine the dynamic and weight-size indicators among the priorities, while using the possibility of a wider variation of engine parameters to obtain given effective power it is possible to obtain an acoustically more favourable combination of these parameters.

The work is executed within the limits of the complex scientific and technical program of a full innovative cycle "Development and introduction of a complex of technologies in areas of exploration and extraction of solid minerals, maintenance of industrial safety, bioremediation, creation of new products of deep processing from coal raw materials at consecutive decrease in ecological impact on environment and risks for population life" (CSTP "Clean coal - Green Kuzbass") on event 2.5 "Development and creation of an autonomous shuttle-type dump truck with carrying capacity of 220 tons (JUPITER project)", with participation of T.F. Gorbachev Kuzbass State Technical University in terms of research, development and technological works.

\section{References}

1. G. Zhironkin, A. Barysheva, M. Khoreshok, M. Tyulenev, Hellmer, Innovative Technologies in Engineering, 12127 (2016)

2. D. Basset, M. Herman, J. Martin, ASLE Transactions, 4, 27, 380-388 (1984)

3. Q. Sunqing, D. Junxiu, Ch. Guoxu, Lubricating Science, 3, 11, 165-172 (1999)

4. A. Efremenkov, A. Khoreshok, S. Zhironkin, A. Myaskov, IOP Conference Series: Earth and Environmental Science, 012009 (2017)

5. A. Kudrevatykh, A. Ashcheulov, A. Ashcheulova, IOP Conf. Series: Materials Science and Engineering, 537, 032033 (2019)

6. A. Kudrevatykh, A. Ashcheulov, A. Ashcheulova, O. Karnadud, L. Rattmann, E3S Web of Conferences 105, 03021 (2019)

7. A. Kudrevatykh, A. Ashcheulov, A. Ashcheulova, K. Urazbaeva, E3S Web of Conferences 174, 03017 (2020)

8. I. Prigogine, R. Herman, Amer. Elsevier Publ. Co., (1971)

9. D. Stenin, N. Stenina, A. Bakanov, Coal in the 21st Century: Mining, Processing and Safety, 256 (2016) 
10. D. Landheer, Additives for lubricants and operational fluids. Ostfildem: Techninshe Akademie Esslingen Druck, 1 (1986)

11. D. Stenin, A. Kulpin, E. Kultayev, E. Kulpina, V. Borovtsov, Coal in the 21 st Century: Mining, Processing and Safety, 116 (2016)

12. Q. Sunqing, D. Junxiu, Ch. Guoxu, Lubricating Science, 3, 11, 165-172 (1999)

13. D. Stenin, N. Stenina, E3S Web of Conferences, (2017)

14. M. Dadonov, A. Kulpin, O. Ostanin, E. Suleimenov, E3S Web of Conferences. International Innovative Mining Symposium, 105, 03009 (2019)

15. M. Dadonov, A. Kulpin, V. Borovtsov, A. Zhunusbekova E3S Web of Conferences Vth International Innovative Mining Symposium, 174, 03018, (2020) 